\title{
Clara Campoamor: una republicana y feminista auténtica
}

\section{Clara Campoamor: a True Republican and Feminist}

\author{
Alberto Gil Ibáñez ${ }^{1}$ \\ Escritor y Ensayista (España) \\ ORCID: https://orcid.org/0000-0001-5487-0659
}

Recibido: 07-05-2021

Aceptado: 01-06-2021

\section{Resumen}

Aunque Clara Campoamor no es una desconocida, hasta tiempos muy recientes su figura no ha comenzado a recibir la atención que merece. Este artículo trata de analizar, de forma objetiva y equilibrada, los aspectos más controvertidos de su biografía, profundizando tanto en su aportación personal y doctrinal al feminismo, como en su papel de cronista de la andadura del Frente popular, el levantamiento militar y los primeros meses de la retaguardia en Madrid. El último apartado resume las lecciones que representa su legado.

Palabras-clave: Historia de España, guerra civil española, feminismo, Campoamor, Frente Popular.

\footnotetext{
1 (alberto.gibanez@gmail.com). Alberto G. Ibáñez ha sido profesor de Derecho Europeo en la Universidad S Pablo-CEU. En la actualidad es miembro del grupo de Reflexión del Instituto Universitario de Estudios Europeos. Doctor en Derecho por el Instituto Universitario de Florencia (Italia) y Doctor (premio extraordinario) en Ciencias de las Religiones por el Instituto Universitario de Ciencias de las Religiones (Universidad Complutense). Pertenece al Cuerpo Superior de Administradores Civiles del Estado y es Diplomado en altos estudios de la Defensa (CESEDEN). Ha publicado numerosos artículos y más de diez libros que abarcan la reforma institucional, el Derecho, la Ciencia Política o la Historia. De ellos cabe destacar el libro colectivo (que coordinó junto a Ramón Marcos): A favor de España: el coste de la ruptura (2014) donde participaron Fernando Savater o Mario Vargas Llosa, La Conjura silenciada contra España (2016) y La Leyenda Negra. Historia del odio a España (2018). Entre sus artículos especializados destacan: "Why Nations Fail. The Relevance of Stability and Culture for European and Global Security", "El enemigo interno de Occidente: una hidra de cinco cabezas. ¿Existe (o debe existir) una cultura europea? Hacia un renacimiento cultural: ¿Procedimientos o valores compartidos? ¿Existe un derecho ilimitado a crear nuevos Estados-nación? Su último libro se titula: La Guerra cultural. Los enemigos internos de España y Occidente, ed. Almuzara, octubre, 2020. Su primera contribución en Araucaria fue "Europa: una historia pendular de unión y división", 22, 45, pp. 527-548.
} 


\begin{abstract}
Although Clara Campoamor is not a stranger, until very recent times her figure has not begun to receive the attention she deserves. This article analyzes, in an objective and balanced way, the most controversial aspects of her biography, deepening both her personal and doctrinal contribution to feminism, as well as her role as chronicler of the beginning of the Popular Front, the military uprising and the first months of the rearguard on the front lines in Madrid. The last section summarizes the lessons your legacy represents.
\end{abstract}

Keywords: History of Spain, Spanish Civil War, Feminism, Campoamor, Popular Front.

Mientras haya un alma noble,
un espíritu valiente,
el nombre de Clara Campoamor no morirá

Luis Español Bouché

\title{
1. ¿Quién fue Campoamor?
}

\subsection{Una gran mujer y una gran española cuestionada}

Sobre Clara Campoamor comienza a haber una bibliografia amplia, si bien paradójicamente sólo recientemente (2005) ha visto la luz en español un libro esencial-La revolución española vista por una republicana-gracias a los esfuerzos y un gran trabajo de traducción y edición a cargo de L. Español. Por su parte, el artículo "España", perteneciente a la obra colectiva La condición de la mujer en la Sociedad Contemporánea (editada en su día por la Universidad de París) fue publicado en español en 2006 gracias a Álvarez Parrondo, quien lo recuperó para su tesis doctoral. En este segundo caso se trataba de un artículo que estaba desaparecido, pero en el primero los obstáculos que encontró el editor para publicar en España un libro de indudable interés para conocer parte de nuestro pasado muestran que nos encontramos ante un personaje incómodo y difícil de encuadrar ${ }^{2}$.

Siendo mujer feminista y republicana convencida, cabría suponer que los homenajes habrían proliferado por doquier. Sin embargo, tal no ha sido el caso hasta tiempos muy recientes, y ello forzados por la fama y prestigio de ser la mujer que introdujo el voto femenino en España, algo difícil de ocultar aunque moleste el resto. Al menos ha conseguido tener más reconocimiento que otra

\footnotetext{
${ }^{2}$ Estando en imprenta este artículo he tenido conocimiento de la publicación de la biografía de Sor Juana Inés de la Cruz, escrita por Campoamor, con prólogo de L. Español (Renacimiento, junio 2021). 
relevante mujer, con la que guarda más de un paralelismo: Mercedes Formica (1913-2002), quien consiguió convencer a Franco para cambiar el Código civil y el penal en la línea que reclamaba Campoamor, pero a la que persiguió su imagen de falangista en sus años mozos.

¿Por qué se trata Campoamor de un personaje incómodo? En primer lugar porque su liderazgo del sufragio femenino se hizo en contra de la posición de la mayor parte de los partidos de izquierda, que consideraban a la mujer de entonces sumisa a la Iglesia y de derechas, y por tanto incapaz de votar con libertad (a ellos). La respuesta de Campoamor, enrolada en el partido radical de Lerroux, el 1 de octubre de 1931, a Victoria Kent -a la que forzaron a defender lo indefendible, mientras la otra mujer, Margarita Nelken, socialista, se ausentó de la votación- figura en los anales del mejor parlamentarismo. Cuestionó la postura de Kent con ejemplos concretos, comparando a las mujeres con lo que sucedía con los varones en parecido tiempo y lugar, y aludiendo a principios básicos éticos y democráticos ${ }^{3}$. A pesar de ello, esa misma izquierda acusaría a Campoamor (y a las mujeres) de su derrota electoral en 1933, mancha que le perseguiría el resto del periodo republicano hasta ser vetada para entrar en Izquierda Republicana, y por ello en las listas del Frente Popular en 1936, quedando así expulsada de la política activa. Este fue su primer "pecado mortal".

Su segundo pecado fue más de lo mismo: ser más liberal que de izquierdas. Cabría suponer entonces que habría sido al menos defendida por el sector liberal y/o conservador de la política española, pero tampoco aquí ha habido gran entusiasmo, ya que Campoamor abandonó el partido radical en 1935 a raíz de la represión de la revuelta de Asturias y sus pactos con la CEDA. Por lo demás, además de liberal fue ferviente republicana y hermana masona. Cabría pensar entonces que habría sido defendida sin matices al menos por los republicanos, pero tampoco ha sido el caso pues su libro arriba mencionado supone una de las más crudas denuncias de la cruel e injusta represión ejercida en la retaguardia durante los primeros meses de la guerra en Madrid, llegando a justificar así en parte su derrota.

En cuanto a su condición de masona forma parte de los más de un misterio que envuelven su biografía. Aunque hoy las grandes logias siguen siendo exclusivamente masculinas, sí existen varias logias femeninas y mixtas, pero en la época de Campoamor las logias no aceptaban mujeres, apareciendo únicamente algunas logias de adopción o dependientes. En España se disputan haber creado la primera logia de adopción la Gran Logia de España (Hijas de Minerva en 1872) y el Gran Oriente Español (GOE), con su Ley de Adopción de agosto de 1892. Campoamor formó parte de la Logia de Adopción "Reivindicación” de Madrid,

\footnotetext{
${ }^{3}$ Ver Juliá 2009: «Discursos de Victoria Kent y Clara Campoamor, 1 de octubre de 1931», 425430.
}

Araucaria. Revista Iberoamericana de Filosofía, Política, Humanidades y Relaciones Internacionales, año $23, \mathrm{n}^{\circ} 47$. Segundo cuatrimestre de 2021. Pp. 211-232. ISSN 1575-6823 e-ISSN 2340-2199 https://dx.doi.org/10.12795/araucaria.2021.i47.10 
que comenzó sus trabajos masónicos en 1932 bajo la tutela de la logia Condorcet del GOE, si bien no se ha encontrado su expediente de iniciación. En todo caso, llama la atención que la masonería se librara de las críticas de Campoamor en cuanto a la patente discriminación que sufrían las mujeres, aunque fuera esta condición, y no el hecho de ser republicana o feminista, lo que impidió que el régimen franquista aceptara su vuelta del exilio cuando lo intentó.

\subsection{Una luchadora por los/sus derechos}

Clara no tuvo una vida fácil no sólo por ser mujer. Nace en 1888. A los diez años pierde a su padre, que había sido un referente en su vida, víctima de fiebre tifoidea. Ello hizo que sólo pudiera estudiar dos años más como interna en un colegio de monjas (hasta los doce años) y que posteriormente debiera ponerse a trabajar para ayudar al sustento familiar y a su madre, ejerciendo desde modista o telegrafista a profesora de mecanografía y taquigrafía. Sin embargo, posteriormente en 1922 (el 20 de abril se matricula en el Instituto Cisneros), con 34 años de edad, decide volver a estudiar logrando en dos años acabar el bachillerato y la carrera de derecho en la que se licenciaría el 19 de diciembre de 1924. Esto es otro de los misterios que rodean su vida, si bien le ayudó cambiar de universidad buscando al parecer las que más facilidades ofrecían ${ }^{4}$.

Entraría en el complejo mundo de la abogacía el 2 de febrero de 1925, aunque la colegiación estaba formalmente abierta a las mujeres en Madrid desde $1920^{5}$. Defiende algunos casos sonados y comienza a hacerse un nombre llegando a co-fundar, junto a otras cuatro abogadas europeas, la Federación Internacional de Mujeres de Carreras Jurídicas. En 1929 da su primer paso en la política, aunque ya era conocida por sus intervenciones en el Ateneo, afiliándose a la Agrupación Acción Republicana. Sin embargo, el partido de Azaña le niega la posibilidad de encabezar ninguna lista en las elecciones de 1931, lo que la lleva a integrarse en el Partido Radical de Lerroux, en teoría más conservador, pero donde consigue ser elegida diputada por Madrid. A partir de su gran éxito al lograr introducir el sufragio femenino en la Constitución, su fama se dispara, pero también sus problemas. En 1933, las primeras elecciones en las que la mujer vota, paradójicamente pierde su escaño, si bien Lerroux le ofrecería la Dirección General de Beneficencia y Asistencia Social, desde la que realizaría una intensa labor.

${ }^{4}$ Ver L. Español, «Introducción» (Campoamor 2018: 9-87), de donde tomamos la mayor parte de los datos biográficos. Ver también, sobre su biografía, el estudio pionero de Concha Fagoaga y Paloma Saavedra, Clara Campoamor: la sufragista española

${ }^{5}$ Por Real Orden de 11 de junio de 1888 se reconoció la posibilidad de cursar estudios académicos, pero solo por Real Orden de 4 de septiembre de 1910, el título facultaría para el ejercicio profesional. El acceso a las profesiones de Notario, Registrador y juez se resistiría algunos años más. Su expediente de colegiación y partida de nacimiento pueden consultarse (Campoamor 2018b: 31-37). 
En 1935 deja el Partido radical por discrepancias sobre la represión en la revolución de Asturias. Poco después atropella a un joven ciclista con su automóvil (Clara por tanto conducía), lo que le granjea diversas críticas, si bien no tanto como a Azaña, quien tras derribar a una señora con su Cadillac no se paró a socorrerla. Trata de ingresar en Izquierda Republicana de Casares Quiroga, pero su solicitud es rechazada, lo mismo que su intento de inscribir su organización "Unión Femenina Republicana” en el Frente Popular. A pesar de ello recibe su triunfo electoral con satisfacción, entre otros motivos porque finalmente se le daba la razón de que otorgar el voto a las mujeres no impedía la victoria de las izquierdas.

Su lucha continúa fuera de la política, tratando de que el gobierno de Casares Quiroga asumiera el "programa mínimo" de su Unión Femenina Republicana. No le daría tiempo para mucho más, pues cuatro días después es asesinado Calvo Sotelo, al que sigue el alzamiento de parte del ejército y la guerra civil. Durante julio y agosto permanece en el Madrid republicano, pero temiendo por su propia vida lo abandona en septiembre, junto a su madre, rumbo a Suiza en barco vía Alicante. En dicho trayecto sufre un intento de asesinato por varios falangistas, quienes le achacan, más que ser republicana, haber introducido el divorcio. Desde entonces vive entre Argentina y Suiza. En tres ocasiones viajará a España durante el franquismo (1948, 1950 ó 1951, y 1953). No es detenida en ninguna de ellas, pero no se le permite quedarse por su condición de masona. En el segundo viaje el Tribunal de Represión de la Masonería le hace una oferta: 12 años de prisión o delatar a antiguos hermanos masones. Clara no acepta, y se vuelve a Argentina. En 1966 se publicará el decreto de extinción definitiva de responsabilidades políticas, suprimiendo la jurisdicción de excepción y concediendo amnistía para los actos cometidos en la Guerra Civil. Tal vez podría entonces haber vuelto, pero tenía 78 años, veía mal y era cada vez más dependiente.

Se queda a vivir en casa de su eterna amiga Antoinette en Lausana, donde moriría en 1972, siendo enterrada días después en el cementerio de Polloe, en San Sebastían, en una tumba de la familia de Pilar Lois, su ahijada.

Veremos seguidamente con más detalle sus dos principales campos de actuación.

\section{Campoamor feminista}

Campoamor fue republicana por varios motivos, pero especialmente porque consideraba que con su advenimiento la mujer, además del voto, conseguiría grandes puestos y avances ${ }^{6}$. No obstante, en cuestión de feminismo,

${ }^{6}$ Otra cosa es que el resultado final colmara sus expectativas: las dos primeras directoras generales 
como en otros aspectos de la vida, no es lo mismo ponerse a tirar del carro, que subirse a un tren en marcha. Ella fue sin duda una pionera en este campo, tras la estela de Concepción Arenal o Pardo Bazán, las precursoras. ${ }^{7}$ Sus reflexiones probablemente no han sido superadas salvo tal vez para caer en la extravagancia. Sin embargo, esta dimensión no le trajo sino disgustos y conflictos, además de algunas pocas buenas amigas. No sólo no sacó partido económico o profesional de esta lucha, como otras personas luego han conseguido, sino que le costó dinero y perder oportunidades de mejores puestos. Por ello, podemos denominarla una feminista "auténtica", que lo fue por pura convicción más allá de cualquier cálculo de interés u oportunismo personal o político.

\subsection{Feminismo y feminidad}

Campoamor no es una feminista de salón, sino una pensadora profunda que llegó a tejer una doctrina coherente y sin aristas, aunque tal vez no todas las feministas de hoy firmarían todas sus ideas. Lo primero que hace es combatir la base tradicional de la percepción, en teoría positiva, de la mujer:

[como] diosa o reina que la caballería andante y la galantería dieron a nuestro sexo en pueblos civilizados (...) la mujer moderna renuncia gustosa a su trono de diosa para integrar la masa de seres humanos (...) y sin melancolía ni pesares reclama, a cambio de su teórico sacrificio, el derecho más universal y bello de $\operatorname{ser}^{8}$.

De forma paralela niega que la función principal de la mujer sea la maternidad o que su realización personal quede condicionada a ser madre, pues "la función maternal no absorbe toda su vida, ni aun un tercio o cuarto de la mujer fecunda, ni embebe todas sus funciones psíquicas".

Cuestiona igualmente la base teórica de una potencial diferencia intrínseca caracterial de la mujer respecto al hombre, sosteniendo que las características que suelen atribuírsele vienen más del ambiente social en que se mueve que

se nombran en 1931 y 1933 , en este último año la primera mujer embajadora, y en 1936 la primera ministra. En todo caso, logra que por primera vez se admita a la mujer como notario, jurado popular, carrera diplomática (secretariado) y puestos técnicos de la Administración (Campoamor 2006: 49). Aunque la República no lograría acabar con la excepción que suponía el acceso a la magistratura, sí consiguió eliminar el delito de adulterio, suprimiendo igualmente la eximente del marido que mataba a su mujer sorprendida el flagrante adulterio (1932), y bajo un gobierno conservador (1935) se suprimió la consideración de la prostitución como "un medio lícito de ganarse la vida", condenando y persiguiendo eso sí al proxeneta. Por último, con la Ley del 11 de noviembre de 1932 se creó un seguro de maternidad, al que contribuía trabajadora, patrono y Estado, y dos descansos diarios de un cuarto de hora para amamantar a su hijo.

${ }^{7}$ La admiración de Campoamor por C. Arenal, convencida krausista, se plasmó en la biografía que le dedicó (Campoamor 2013). Y de hecho existen varias curiosas coincidencias históricas y biográficas entre las dos (Manzanero 2019: 553, 554).

${ }^{8}$ Campoamor, «La nueva mujer ante el derecho» en Campoamor 2018b: 9-65, 10

${ }_{9}$ Campoamor, «La mujer y su nuevo ambiente» en Campoamor 2018b: 117-168 
de ninguna esencia específica ${ }^{10}$. Pronostica que a medida que cambie ese ambiente cambiará la mujer, lo que redundará en beneficio no sólo de ésta sino del propio hombre, pues su unión con ella "se espiritualizará" (Campoamor, "La mujer y su nuevo ambiente" en Campoamor 2018b: 152). Será una mujer menos sensiblera, menos obsesionada por el culto exagerado y a veces absurdo por la moda - con la complicada tortura de los tacones altos y afilados y las opresiones del corsé-, menos sujeta a periodos frecuentes de crisis nerviosas e histerismo (efecto derivado en gran parte de su enclaustramiento); más madura, más completa, bella no solo por el exterior sino por su vida interior: "Quien hace un siglo se hubiera inevitablemente encaramado a una silla ante un ratón, se lanza a la selva a cazar leones o lidia astados en una plaza" (Ibid: 127). Llega a aceptar que la "vieja" mujer, dentro del "arte de agradar", ha perfeccionado el ejercicio de la mentira y la falsedad, deformándose a sí misma, como arma inherente al débil para dominar al hombre, que se presenta como el fuerte (Ibid: 136 y 137).

En parecido sentido, sostiene que una mujer más completa, de espíritu y cerebro, también beneficiará el ejercicio de la maternidad, y sobre todo no privará a la sociedad de su aporte una vez acabe su "holocausto al hijo, al continuador, todo el tiempo que éste reclame sus atenciones", sin olvidar la "deuda que la Sociedad contrae con la madre" (Ibid: 131 y 132). La madre, educadora de generaciones, no puede encontrarse en "igual situación legal que los dementes o penados, y en inferioridad legal con la mujer soltera, que conservó sus prerrogativas jurídico-legales, no contribuyendo al cultivo de la especie" (Ibid: 151). Por otra parte, el divorcio sólo puede funcionar cuando la mujer adquiera una capacidad económica que le permita independizarse, no existiendo dignidad personal que no tenga por base la aptitud económica.

No obstante, aunque la nueva mujer-mujer no ambiciona la categoría de diosa, y le basta con ser considerada en la medida que el varón, no desdeña la galantería ni cree que ha muerto la vieja costumbre de oponerse a lo esencial para claudicar en lo accesorio. No se debe confundir su transformación espiritual con una nueva fase de masculinismo. Aspira a la identidad legal y moral con el varón, pero no a la identidad fisiológica para lo que la mujer no debe renunciar ni en parte ni en nada a las cualidades que la caracterizan sexualmente (Ibid: 133 y 134). Por ejemplo, su apartamiento de la dictadura de la moda será pareja a lo que ya experimentó el hombre al separarse del amaneramiento y la frivolidad que invadía las cortes en los siglos XVII o XVIII, cuando el hombre se vestía de manera tan disparatada como la mujer (Ibid: 141 y 142). Por otra parte, la mujer moderna, nutrida de actividad y de sano equilibrio no será menos graciosa y bella que en otras épocas; por el contrario, podrá alcanzar una belleza más elevada, más sana y plena (Ibid: 157 y 160). Por último, esos

${ }^{10}$ Campoamor, «La nueva mujer ante el derecho» en Campoamor 2018b: 17 
cambios afectarán al concepto del amor, liberando por una parte a la mujer de su dependencia en este campo pues el amor no es toda la vida de la mujer, sino parte de ella, pudiendo convivir con otros anhelos e ideales individuales. Por otro lado, el amor se beneficiará de la evolución de la mujer, dándole mayor parte de espiritualidad, sin perder un átomo de sensualidad, liberándolo de una esclavitud que sólo transparenta flaqueza (Ibid: 167 y 168).

\subsection{La discriminación especial de la mujer casada}

La discriminación en la España de la época venía paradójicamente sobre todo de estar casada y ser madre, lo que en lugar de ser un "plus" se convertía en el pretexto para limitar su capacidad y movimientos: "la casi totalidad de las restricciones impuestas a la mujer en el derecho privado lo son, no por razón de sexo, sino por razón de matrimonio" "11. Campoamor reconoce los avances sociales y que a la mujer no le estaba cerrado ni el taller, ni la escuela, ni el aula. Las limitaciones venían de la imposibilidad de acceder a todo tipo de empleos u obtener igual remuneración que el hombre, así como de no poder abandonar la casa paterna antes de los 25 años. Pero sobre todo del hecho de ser mujer casada, la cual sin la autorización del marido sólo podía hacer testamento y cumplir con sus obligaciones con los hijos que hubiera tenido con otro hombre (art. 62 del Código civil).

En este sentido, durante un tiempo, para impedir a la mujer el acceso a la profesión de notario, se aludió a la obligación de seguir ésta a su marido, su incapacidad para testificar en testamentos, su falta de libertad para disponer de sus bienes o la necesidad de licencia marital para asumir la responsabilidad civil propia de su cargo ${ }^{12}$. Del mismo modo necesitaba licencia del marido para comparecer en juicio, obligarse, contratar o disponer de sus propios bienes. En cuanto al régimen de gananciales ("figura jurídica de una extraordinaria generosidad para la mujer") ${ }^{13}$, que era el que se aplicaba con carácter general salvo convención en contrario, Campoamor reconoce que beneficiaba a la mujer cuando no aportaba al caudal familiar por no trabajar fuera de casa, pero a cambio la administración de los bienes quedaba reservada al marido, quien también administraba los bienes parafernales procedentes de la dote, y ello aunque en la práctica la administradora real fuera en la mayoría de los casos la mujer. También la discriminación se extendía al Código penal, que preveía el delito de adulterio para la mujer en todo caso, pero para el hombre sólo cuando resultara escándalo público o menosprecio de la mujer.

\footnotetext{
${ }^{11}$ Campoamor, «Antes que te cases (el derecho privado)» en Campoamor 2018b: 67-116, 67.

${ }_{12}$ Así se estableció en un dictamen del Consejo de Estado, que reconocía que esas disposiciones del Código Civil podían ser injustas, pero que no podían ser modificadas por resolución administrativa, «aunque la mujer tiene plenitud de libertad civil no siendo casada» (Campoamor, «La nueva mujer ante el derecho» en Campoamor 2018b: 33.

${ }^{13}$ Campoamor, «Antes que te cases (el derecho privado)» en Campoamor 2018b: 95
} 
¿Por qué esta situación? Campoamor reconoce que todo sistema debe tener alguna justificación para perdurar en el tiempo, y la de éste sería "proteger" a la mujer casada a cambio de "obediencia" al marido. Pero se pensaba en un tipo de familia adinerada (clases privilegiadas) que podía permitirse el lujo de que la mujer no trabajara y tuviera ayuda en casa, mientras se olvidaba al mayor número de familias donde la mujer vivía explotada en casa y además debía trabajar fuera para completar el sustento familiar. Esta situación fue objeto de una conferencia donde Campoamor aconseja a la mujer casada que, antes de contraer matrimonio, firmara unas capitulaciones, permitidas por el art. 1.315 del Código civil de entonces ${ }^{14}$. En ellas el marido debería aceptar algunas condiciones que la mujer tuviera libre disposición de sus bienes, que la administración de gananciales se llevara conjuntamente y aun que la ejerciera sola la mujer, que se autorizase de inicio a la mujer para contratar, ejercer oficio, profesión o industria, viajar, obtener pasaporte, comprar, vender, obligarse..., e incluso exigir al marido garantías proporcionales a su dote o bienes parafernales, si hubiera cedido la administración de estos al marido (Campoamor 2006: 66). De hecho, muchas capitulaciones de este tipo se firmaban, estando sin embargo prohibido, por influencia del código napoleónico, que se alteraran o firmaran una vez celebrado el matrimonio (Campoamor, "Antes que te cases (el derecho privado)" en Campoamor 2018b: 108, 110).

En este contexto, no es de extrañar que ella dé a entender que la situación ideal de la mujer en esa época fuera la de viuda rica, y que por ello se observaban tantas viudas "alegres", no sólo en nuestro país sino en la propia Francia (Ibid: 94 y 105). No llega, sin embargo, a aventurar que, siendo entonces las señoras las dueñas exclusivas de los fogones, algo tuviera que ver con esa situación el que la esperanza de vida de los maridos fuera notablemente inferior al de sus esposas. En todo caso, acaba la citada conferencia con un refrán español, que resultaría igualmente aplicable en la actualidad, por ejemplo a la hora de prevenir algunos casos de violencia de género: "Antes que te cases, mira lo que haces" (Ibid: 116).

\subsection{Tradición jurídica española versus foráneas}

Una de las aportaciones de Campoamor que ha pasado curiosamente más desapercibida es la que achaca la evolución negativa del derecho español en el trato de la mujer a la influencia francesa, y en especial a la nefasta orientación al respecto que introdujo el Código civil napoleónico, lo que no es de extrañar dado que Napoleón sostenía que "la mujer sólo tiene el valor de

${ }^{14}$ Existían algunas limitaciones curiosas al contenido de esas capitulaciones, por ejemplo, no se podía estipular que la mujer tendría obligación de mantener al marido, a fin de que éste no trabaje, pues ello sería contario a la moral, pero tampoco que la mujer no tuviera obligación de obedecer al marido, pues ello sería contrario a la ley (Ibid: 107).

Araucaria. Revista Iberoamericana de Filosofia, Política, Humanidades y Relaciones Internacionales, año $23, \mathrm{n}^{\circ} 47$. Segundo cuatrimestre de 2021. Pp. 211-232. ISSN 1575-6823 e-ISSN 2340-2199 https://dx.doi.org/10.12795/araucaria.2021.i47.10 
máquina reproductora de granaderos de la guardia"15. Y a él se debe igualmente la pintoresca teoría del hogar vestido de jerarquía militar, donde el hombre ejercería de coronel y la mujer de simple soldado ${ }^{16}$.

Por el contrario, en la tradición jurídica española, desde el derecho germánico (godo) la posición de la mujer era más vigorosa. Por de pronto, como madre natural a efectos de poder probar la paternidad del varón y obligarle al sustento de la prole (lo que se recoge en las Siete Partidas y las Leyes de Toro), pero también como miembro responsable y capaz de la comunidad ciudadana. De hecho, parte de estas facultades jurídicas de la mujer (capacidad de tutela desde los 20 años, no perder la patria potestad por segundo matrimonio, capacidad para testificar desde los 14 años...) quedaron recogidos en algunos Fueros, como el general de Aragón o el de Vizcaya, mientras se perdieron en la legislación común por influencia francófona y, en parte, también del derecho romano. En Aragón las mujeres podían ser tutoras y tenían derecho al "usufructo universal" de todos los bienes del cónyuge difunto, en las mismas condiciones que el varón, mientras no se casara de nuevo. El "Fuero de Baylio", por su parte, concedido a la ciudad de Alburquerque en 1778, sostenía que "todos los bienes que los esposos aportan al matrimonio o que se adquieren durante el matrimonio les pertenecen conjuntamente" (Campoamor 2006: 68). Mientras el Foro de Tortosa ("Código de costumbres de Tortosa"), que data del siglo XII, concedía a la mujer no casada la misma condición en la familia que su hermano o su padre: disponer libremente de sus bienes, poder contratar con carácter oneroso o gratuito, y vender libremente sin tener que dar cuentas al marido del uso del resultado o frutos de esos bienes (Campoamor 2006: 58 y 71).

Una excepción a esa tendencia era, sin embargo, el Derecho foral catalán que, al seguir estrictamente el Derecho romano y la institución del "hereu", perjudicaba notablemente a la mujer, incluida la viuda, en contraposición por ejemplo con la castellana ${ }^{17}$. En este sentido, instauró el "derecho de primogenitura", según el cual los hijos excluían a las hijas de la sucesión de sus padres, además de que hijas y nietas podían ser desheredadas por "haberse dedicado a la prostitución, cosa que no ocurriría con los hombres (Campoamor 2006: 56).

Campoamor reconoce igualmente que la "sociedad legal de gananciales" era una supervivencia del derecho germánico-español recogido en las leyes de las Partidas por Alfonso X, resultando más beneficiosa para la mujer que el Derecho romano al que se debía por ejemplo la institución de la dote (Campoamor 2006: 61 y 65). En materia penal el antiguo Derecho español

\footnotetext{
${ }^{15}$ Campoamor, «La nueva mujer ante el derecho» en Campoamor 2018b: 54-58, 56

16 Ibidem, 150

${ }^{17}$ Campoamor, «Antes que te cases (el derecho privado)» en Campoamor 2018b: 96.
} 
admitía asimismo la ignorancia de la ley como atenuación de pena para soldados, sacerdotes y mujeres, si bien aquí se mostrará claramente en contra de este supuesto privilegio (Campoamor, 2006, p. 76).

Rompe de esta manera, tal vez sin ser muy consciente, con dos mitos: el de la modernidad inherente a la revolución francesa y al derecho romano, y el del sentido arcaico del derecho consuetudinario tradicional español. De hecho, nuestro país es desde tiempo inmemorial una excepción a la costumbre europea, incluso nórdica, de la pérdida del apellido de la mujer casada y que por tanto la prole que ella ha dado a luz y criado pase a llevar el apellido exclusivo del padre (Ibid: 57). A este respecto, se echa de menos que hubiera igualmente recordado que la tradición sucesoria en España (más en Castilla que en Aragón), a diferencia de la francesa, preveía que heredaran el trono las mujeres, y de hecho Castilla tuvo grandes reinas con mando en plaza, como Isabel I o doña Urraca, y grandes regentes como María de Molina o doña Berenguela que renunció al trono voluntariamente en favor de su hijo Fernando III, por ser conveniente en esos tiempos que el rey encabezara las tropas. De hecho, las guerras carlistas nacen, entre otras causas, porque esa tradición española (y castellana) fue alterada al llegar los borbones, lo que paradójicamente hace que los autodenominados "tradicionalistas" estuvieran defendiendo en realidad una tradición foránea.

Reconoce del mismo modo que la legislación española nunca prohibió a la mujer el ejercicio de profesiones liberales, en realidad más por falta de previsión que por generoso reconocimiento -el problema venía de los reglamentos que regulaban las distintas profesiones-, y que podían acudir libremente a los cursos de la Universidad, lo que permitió a Isidra de la Cerda y Guzmán en el siglo XVIII acabar de profesora de filosofía en la Universidad de Alcalá o a Concepción Arenal en el XIX asistir a los cursos de derecho de la Universidad de Madrid (Campoamor 2006: 50 y 51). De nuevo, sin embargo, parece olvidar aquí otros casos, como los de (a principios del siglo XVI) Luisa de Medrano y Francisca de Nebrija, profesoras de la Universidad de Salamanca, o Beatriz Galindo, "La Latina".

Por último, toma nota de algunos avances previos a la República, como el Decreto-ley de 21 de agosto de 1923, que proveía a la protección de la maternidad para las trabajadoras con un pequeño subsidio y el derecho al descanso de seis semanas antes y después del parto, lo que fue ampliado en 1924 y 1925 a las mujeres funcionarias (Campoamor 2006: 54). 


\subsection{La cuestión esencial del voto}

Aunque habían existido algunos intentos previos (1905 y 1907), el primer logro parcial del sufragio femenino sucedió paradójicamente durante la dictadura de Primo de Rivera, cuyo Estatuto municipal de 1924 reconoció a las mujeres emancipadas, no sujetas a la tutela del marido o el padre, que fuesen cabezas de familia, la posibilidad de ser electoras y elegibles en las elecciones municipales. Para Campoamor esta pequeña conquista representaba una mera concesión paternalista y no un reconocimiento de derechos. Pero lo que más le dolió fue el decreto de mayo de 1931 del Gobierno provisional de la República, que modificó la ley electoral de 1907 para reducir la edad electoral del varón a 23 años mientras dejaba a la mujer equiparada graciosamente a la condición de los sacerdotes, limitándolas a poder ser elegibles, pero no electoras:

Si quería respetar íntegramente la libertad de la futura Cámara en cuanto no fuera indispensable, no debió osar modificaciones tan importantes, y si creó que debía hacerlo, ¿A qué tomar la mitad y no todo? ¿Por qué no concedió también a la mujer el derecho de electorado? (Campoamor 2001: 24)

Califica al gobierno provisional de hipócrita, pues presumiendo de anhelos modernizadores, lo que pretendía en realidad era "llevar a la Cámara, con votos exclusivamente masculinos, a una sola mujer, de espíritu no muy reivindicativo, de ánimo no muy combativo" (Campoamor 2001: 29). En otras palabras, una mujer florero cara a la galería pero que se quedara calladita. Con Campoamor pincharon en hueso, y eso que venía como candidata de un partido republicano más de derechas que de izquierdas, como era el radical de Lerroux. En todo caso, esa previsión produjo la paradoja de que Campoamor y las otras dos mujeres elegidas en las primeras elecciones (Victoria Kent y Margarita Nelken) lo fueran sin poder votarse a sí mismas.

La lucha de Campoamor por el voto comenzó desde muy pronto, una vez elegida, no faltando ni un solo día a las deliberaciones de la nueva Cámara, sobre todo en cuanto concernía a la redacción de la nueva Constitución. El primer golpe lo recibió de la propuesta del art. 23, que rezaba: "Se reconoce en principio la igualdad de los dos sexos". La coletilla "en principio" no era inocente, pues existía el precedente de la Constitución de Weimar, donde una similar redacción había servido como pretexto para que las alemanas no tuvieran igualdad de derechos, de lo que ella era consciente. Tras una lucha denodada en el parlamento, y "después de un áspero debate y por mayoría de votos" (Campoamor 2006: 45), Campoamor no sólo logra eliminar dicha expresión sino que, con la oposición de Victoria Kent y parte del partido socialista encabezado por Indalecio Prieto, consiguió que los arts. 25, 36 y 53 de la Constitución reconocieran sin género de dudas la prohibición de 
cualquier "privilegio jurídico" por sexo, la consagración de los mismos derechos electorales de "los ciudadanos de uno y otro sexo", siendo elegibles los ciudadanos mayores de 23 años, "sin distinción de sexo ni estado civil".

No obstante, esta cuestión le granjeó pocos parabienes y muchos reproches, hasta el punto de que tituló su libro sobre esta cuestión "Mi pecado mortal", publicado poco después de la victoria del Frente Popular, donde por fin pudo defender que su victoria personal era en realidad de todos, pero especialmente de la mitad de españoles que eran españolas. Sin embargo, los resultados prácticos de su lucha pueden considerarse algo modestos, pues sólo hubo cuatro mujeres elegidas en 1933 (ya con libertad de voto, no consiguiendo paradójicamente ser diputada la propia Campoamor) y seis en 1936. Campoamor lo justifica por "la falta de confianza de las mujeres en su propio sexo" (Campoamor 2006: 47), si bien también era cierto que los partidos de todas las tendencias proponían pocas mujeres como candidatas.

Por último, no se ha reconocido suficientemente que la lucha de Campoamor por el sufragio femenino no se limitó a España, logrando, junto a su gran amiga Antoinette Quinche, que el primer cantón suizo donde se reconociera el voto femenino fuera Vaud (capital Lausana), donde vivían en 1959. A nivel federal, las mujeres suizas debieron esperar hasta 1971, e incluso en algunos cantones y municipios hasta 1991, donde se lograría la igualdad total en Suiza que Campoamor ya no vio.

\section{Campoamor republicana}

Para Campoamor, ser republicana no solo era un medio para lograr más derechos para las mujeres, sino también su forma de ser española y liberal. Pero de nuevo cometería su "segundo pecado mortal" por exceso de honestidad personal y coherencia con sus ideas, comenzando por firmar un voto particular al Estatuto catalán, junto a otros diputados del partido radical, que señalaba:

Es obligatoria la enseñanza en castellano en todas las escuelas primarias de España. En el caso de que las regiones autónomas organicen enseñanzas en sus lenguas respectivas, el Estado mantendrá, en aquellos Centros de instrucción de todos los ramos, la lengua oficial de la República ${ }^{18}$.

No obstante, fue su libro, antes citado, sobre la vida en la retaguardia de Madrid (2018a) lo que la granjearía más disgustos.

${ }^{18}$ Citado por L. Español, 2018, p. 26.

Araucaria. Revista Iberoamericana de Filosofía, Política, Humanidades y Relaciones Internacionales, año $23, \mathrm{n}^{\circ} 47$. Segundo cuatrimestre de 2021. Pp. 211-232. ISSN 1575-6823 e-ISSN 2340-2199 https://dx.doi.org/10.12795/araucaria.2021.i47.10 


\subsection{El valor de su testimonio}

Algunos historiadores tienden a despreciar las fuentes de primera mano por "subjetivas". Como si toda investigación histórica no tuviera un punto de subjetivismo, incluso cuando no se lleva a cabo por "historiadores de un solo ojo", al servicio de una causa, ideología o partido. A fin de cuentas, como nos recuerda Nietzsche, "todo es interpretación". Pero puestos a interpretar los acontecimientos de un determinado periodo resulta relevante contar con testimonios directos, los cuales no pueden ser despreciados, mucho menos cuando provienen del mismo bando que es cuestionado, siendo una de las escasas muestras de una sana autocrítica. En este sentido, el libro de Campoamor (2018a) resulta revelador, porque no se trata de una autobiografía tendente a salvar su propia figura, sino una mera crónica, como testigo directo de lo que ella ve, no teniendo más motivos para escribir lo que escribió que describir la realidad tal como se le presentaba.

Existen otros testimonios de "primera mano", normalmente en forma de biografías, que narran los últimos años de la República y el desarrollo de la guerra civil (entre otros el de Azaña), cada cual tratando de defender su papel y criticar el de los demás. Sin embargo, es fácil caer en la trampa de seleccionar sólo lo que interesa, según convenga a la posición personal de partida (ideológica o no) del intérprete, de estos testimonios directos. Un vicio del que no están libres ni los más reputados historiadores ${ }^{19}$. Un ejemplo, que comparte valor y enfoque con el libro de Campoamor, son las memorias de Julián Zugazagoitia (1968), estrecho colaborador de Negrín - de cuyo gobierno llegó a ser ministro de Gobernación y Secretario General de Defensa Nacional-, quien se atrevió a describir, además de la traición de los nacionalistas vascos y catalanes a la República, el hecho de que, desencadenado ya el golpe y con la guerra en su apogeo, cuando la unidad de visión y acción resultaba más esencial eran constantes los enfrentamientos entre las máximas autoridades de la República: Largo Caballero contra Besteiro, Azaña contra Negrín..., incluso por cuestiones banales o de propio interés.

Sin embargo, la obra de Zugazagoitia como la de Campoamor han pasado mayormente desapercibidas tal vez por tratarse de crónicas que dan cuenta, desde

${ }^{19}$ Destacan las críticas vertidas contra las Memorias de uno de los personajes que más hicieron por traer la República, Alejandro Lerroux, tal vez por haber cometido el pecado de avenirse a presidir un gobierno en coalición con la CEDA de Gil Robles. Sobre su libro La pequeña historia (acabado de escribir en Estoril en noviembre de 1937), Javier Tusell, por ejemplo, dijo que se trataba de «violentas diatribas seniles» o «amasijo de pequeñas ambiciones y conspiraciones», al tiempo que acusaba al político barcelonés de «real indigencia programática». Mientras, paralelamente, el mismo historiador destacaba la «moderación e imparcialidad de juicio de Martínez Barrio» en sus Memorias, opiniones «altamente fiables por la excepcional situación de Martínez Barrio» (como si Lerroux hubiera sido una figura menor en comparación), tal vez por acabar separándose del primero para formar parte del Frente Popular (Tusell, 1984: 21, 22, 26). En todo caso, la obra de Lerroux, aunque se discrepe de su visión, resulta de indudable interés, pues incluye datos, reproduce diálogos y está muy bien escrita, aunque él mismo reconoce: «Hechos y detalles que se han traído a estas páginas por mi pluma han podido parecer, en algunos casos, alardes de una vanidad insatisfecha, que busca en la exhumación complacencias que no le dispensó la atención pública al parecer» (Lerroux 1963: 498). 
dentro del propio bando republicano, de lo que oyen y ven, gozando de una credibilidad peligrosa para los que previamente han decidido que la guerra civil fue una simple historia de buenos y malos, claramente pre-definidos sin matices. Y eso que no puede aducirse, como en el caso de Lerroux, que fueran "falsos" republicanos que se pasaran a la derecha. Zugazagoitia acabó, tras ser capturado por la policía nazi en Francia, siendo condenado a muerte en consejo de guerra y fusilado por el bando franquista, mientras Campoamor murió en su exilio en Suiza.

Por el contrario, el valor de este tipo de narraciones surge de no estar contaminadas de ningún prejuicio ideológico "pro" y "contra”. Campoamor no tenía nada que ganar y mucho que perder contando lo que contaba; lo hizo para que sucesos semejantes no se repitieran:

La bibliografía sobre la guerra civil española es inmensa, pero con frecuencia
cargada de subjetividad. La obra de doña Clara es del mayor interés por su fecha,
tempranísima, por su contenido y forma, por la sobriedad de la exposición,
y, sobre todo, por su absoluta honestidad. Campoamor dice lo que vivió, lo
que sabe o cree saber, y trata de explicar el origen de la tragedia (...) algunos
capítulos pueden ser considerados como fuente primaria de información para la
historiografía de la Guerra Civil (Español 2018: 69, 71).

Y apostilla Andrés Trapiello: "Las ideas de Campoamor fueron netas, ponderadas y, acaso lo más prodigioso, con una meridiana lucidez, ya que las exponía en el mismo 1936" (Trapiello 2019: 316). Sin embargo, dado que sus observaciones no beneficiaban al bando republicando, algunos autores y autoras han tratado de quitar valor a su testimonio acusándola de falta de perspectiva y carencia de matices, e incluso planteando que se arrepintió de haberlo escrito, algo sumamente improbable pues "de haberse arrepentido, no habría escrito Heroísmo criollo con Fernández-Castillejo" (Español 2018: 74 y 77). Campoamor ya estaba acostumbrada a batallar contra todos, galopando solitaria a lomos de sus principios, si bien es cierto que cuando llegaron a sus oídos los excesos del otro bando, prefirió no insistir en la difusión de un libro que ya le había hecho perder más de una amistad.

\subsection{Crónica del fin de la Revolución española (Campoamor 2018a)}

\subsubsection{De la victoria del Frente Popular al 18 de julio: los prolegómenos (Caps. I-III, 97-113)}

Campoamor nunca llega a justificar la rebelión militar, pero sí describe el contexto que la hizo, primero, posible, y que a la postre colaboró en una victoria que a priori tenían muy difícil los rebeldes. Comienza explicando algunos aspectos de la andadura del Frente Popular desde que ganó las elecciones y en 
particular las semanas antes del alzamiento. Describe con testimonios directos (por ejemplo, de Martínez Barrio) y datos -número de saqueos, ocupación de tierras, incendios de iglesias y otros edificios públicos y atentados con resultado de muerte- la situación de caos y división interna que se vivía dentro del gobierno y de los partidos que sustentaban el Frente Popular y cómo se impusieron finalmente los elementos más extremistas.

Destaca la apresurada y total amnistía a los implicados en la revolución de octubre, incluidos los del intento de secesión catalana, antes incluso de constituirse formalmente el nuevo parlamento, y la subsiguiente destitución del Presidente de la República Alcalá Zamora. Ésta última especialmente molestó a Campoamor porque se hizo vulnerando frontalmente la propia Constitución republicana, cortando abruptamente su mandato de cuatro años con el fin de nombrar en su lugar a Azaña, el antiguo ministro de la Guerra al que gran parte del ejército veía como su enemigo, en una maniobra impulsada y dirigida por "ese espíritu letal para la República, que ha sido don Indalecio Prieto" (Ibid: 102). La situación social estaba presidida por la anarquía y una huelga interminable a cargo de un "frente obrero" preconizado por Largo Caballero, que entre otras cosas llevaba a que cada día se hicieran explosionar cinco o seis bombas de dinamita en edificios en construcción.

A ello se unían los enfrentamientos callejeros entre marxistas y falangistas. De estos últimos decía que "nunca habrían pasado de ser un puñado de amigos si los errores acumulados por los republicanos y marxistas no hubiesen favorecido su movimiento" (Ibid: 107). Se reaccionó con numerosos arrestos, con la sorpresa de que entre los fascistas se encontraban hijos de conocidos miembros del Frente Popular $^{20}$. La declaración de Casares Quiroga de que su gobierno adoptaría una posición beligerante contra el fascismo no hizo sino encender los ánimos. Pero fue también la posición un tanto pasiva de Gil Robles ante los frecuentes actos de violencia, incendios y saqueos lo que hizo crecer a la Falange.

En este contexto tuvo lugar el asesinato de Calvo Sotelo el 12 de julio, que se presenta como una venganza contra el asesinato previo del teniente Castillo, atribuido en un primer momento a elementos fascistas ${ }^{21}$. Calvo Sotelo acepta salir de su casa porque pone su confianza en el "honor de un oficial de la Guardia Civil" que acompañaba a los guardias de asalto, en realidad un militante del partido socialista. El gobierno no adoptó ninguna sanción contra los culpables, que se paseaban libremente por las calles tras el magnicido, siendo suspendidas las Cortes para evitar el escándalo. Hay que tener en cuenta que previamente, el diputado Galarza había declarado que "un atentando contra él estaría plenamente justificado".

${ }^{20}$ De haber vivido la Transición, tal vez no le hubiera sorprendido el paralelo de ver que entre los más fieros antifranquistas se encontraban los hijos e hijas de reputados altos cargos franquistas.

${ }^{21}$ Campoamor da a entender que la autoría entonces no estaba clara. En realidad, fueron requetés del Tercio de Madrid, y no falangistas, como ha demostrado posteriormente Ian Gibson (1982, p. 207) 


\subsubsection{Del estallido de la sublevación a su fracaso en Madrid (Caps. IV-IX, 114-136)}

El alzamiento se inicia el 17 de julio en la guarnición de Melilla, si bien el 18 se extiende a las principales plazas militares. Ante esta situación el gobierno toma una decisión polémica, que le pesa a Campoamor: entregar armas a las fuerzas políticas de izquierda, si bien las organizaciones obreras ya estaban previamente armadas. Los anarcosindicalistas se hicieron además con los depósitos de armas de los cuarteles que iban siendo tomados (Montaña, Cuatro Vientos, Alcalá y Guadalajara). Aunque la participación de las milicias "ciudadanas" fueron esenciales en un primer momento para evitar que Madrid y Barcelona cayeran del lado de los sublevados, a la larga traería más problemas que ventajas, pues con ello "el gobierno entregó la España gubernamental a la anarquía" (Ibid: 124). El propio General Goded, tras venir en vuelo de las Islas Baleares para ponerse al frente de los sublevados en Barcelona, se encontró una situación difícil de enderezar, siendo detenido por una mujer sin ofrecer resistencia. Aunque reconoció públicamente su fracaso, como le instó Companys a hacer, fue fusilado tras un juicio sumarísimo. Con esta ejecución y la posterior del general Fanjul y sus compañeros del cuartel de la Montaña -muchos de los cuales tras haberse rendido, como ocurrió en Cuatro Vientos, aunque los periódicos informaron de que se habían suicidado- quedó claro que la lucha sería a muerte. La excusa que dieron los "gubernamentales" (así los llama Campoamor) era que en Extremadura y Andalucía también se fusilaba sin formación de causa a elementos de izquierda.

Campoamor se hace eco de las dos tesis que corrieron entonces sobre las razones de una sublevación que tenía aires de precipitación. Los gubernamentales presumían de saber que en realidad estaba prevista para octubre de 1936, pero que el asesinato de Calvo Sotelo la precipitó, lo que les habría pillado desprevenidos. Por la otra parte, sin negar la importancia del asesinato de Calvo Sotelo, aludían al intento de adelantarse a una revolución social-comunista prevista para agosto. Lo más interesante de esta parte es que Campoamor discrepa de que en la guerra civil se enfrentaran fascismo contra democracia: "La cuestión no es tan sencilla. Ni el fascismo puro ni la democracia pura alientan los dos adversarios" (Ibid: 132). Entre los ejemplos que da para ello está que en las primeras semanas el bando sublevado todavía cantaba el himno de Riego y utilizaba la bandera republicana, y que sólo a partir del 15 de agosto se volvió a la bandera rojigualda, pero manteniendo el escudo de la república en lugar del monárquico. De forma paralela, en Madrid la bandera republicana fue sustituida por la bandera roja socialista o la rojinegra anarquista. A ello añade el análisis detallado de los distintos elementos diversos que componían los dos bandos (que incluían destacados militares republicanos 
en el nacional), llegando a la conclusión que fuera cual fuera el desenlace de la guerra, en España se instauraría una dictadura de uno u otro signo (Ibid: 133135).

\subsection{3 ¿Por qué la República perdió la guerra? Errores y debilidad gubernamental (Caps. X-XV, 137-182)}

Campoamor parte de la falta de legitimidad de la sublevación, pues se alzaron contra un gobierno elegido en las urnas en febrero de 1936, vulnerando el estado de derecho. Sin embargo, este hecho no le impide ahondar en las causas más profundas del conflicto, admitiendo algunos errores propios del bando republicano, que colaborarían a la postre en su derrota en la guerra. En primer lugar, constata que España no era un país de partidos sino de opinión, dado el bajísimo número de militantes, lo que permitía continuos cambios de tendencia que los partidos trataban de contrarrestar ofreciendo promesas o reformas (algunas alocadas) que luego no podían cumplir. Otro problema era una ley electoral que obligaba a hacer grandes coaliciones de partidos con posiciones contradictorias, donde a menudo se imponían los grupos más extremistas que forzaban al resto a tomar como primera medida acabar con lo que hubiera hecho el anterior gobierno. Pasó en 1934, con la derogación de la legislación reformadora que había introducido la izquierda, y volvió a pasar en 1936, tal vez más explícitamente, con la amnistía a los implicados en la revolución de octubre, reincorporando en sus puestos a los sublevados con el pago de salarios atrasados, lo que implicaba un claro apoyo al anterior intento de subvertir la legalidad republicana.

Pero lo que hizo perder la guerra a los gubernamentales fue su creciente debilidad, debida a tres factores "internos": la carencia de técnica, la ausencia de disciplina y la desmoralización de la retaguardia. En relación al primer punto señala:

Los partidos españoles de extrema izquierda con frecuencia han mostrado un profundo desprecio hacia la técnica en todos los campos, por lo menos hacia la técnica "burguesa", la única que lógicamente podía existir en el país con el advenimiento de la República. A su juicio era suficiente poseer la fe y el entusiasmo revolucionarios para cumplir con cualquier tarea en el gobierno (Ibid:147).

Ello se demostraría, por ejemplo, en cómo no se supo sacar partido de su superioridad naval, una vez arrestados o ejecutados sus oficiales. El desprecio por la técnica iba unido a la falta de disciplina, hasta el punto de que, al menos en los primeros momentos, los comunicados del Ministerio de la Guerra daban idea de un ejército sin jefes, mientras los periódicos proclamaban que 
la revolución española no necesitaba de ningún Lenin o Robespierre, bastaba "Juan Español".

Pero el elemento fundamental que contribuyó a la pérdida de la moral de los republicanos, y a la postre su legitimidad, sería el clima de terror que se impuso en la retaguardia, especialmente en Madrid y Barcelona, aunque Campoamor se referirá lógicamente con mayor detalle a los de la capital donde vivía. Si bien reconoce que las acusaciones de crueldad parten de los dos bandos, "del lado gubernamental quiso la suerte que fuese yo testigo más o menos directa de los excesos cometidos" (Ibid: 180). Patrullas de milicianos por las calles hacían arrestos, juicios populares y fusilamientos. Primero se persiguió a elementos fascistas, luego a personas pertenecientes a la derecha, más tarde a sus simpatizantes, luego a miembros del partido radical de Lerroux, y después a personas de izquierda republicana. Hubo ejecuciones en masa en la Casa de Campo, todos los días aparecían 60, 80 o 100 muertos en los alrededores de la ciudad. Se buscaba a la gente en su casa o en su trabajo, y si no estaban se llevaban a alguien de su familia. La falta de seguridad era tal que hasta personas pertenecientes a partidos en principio no perseguidos por el gobierno, pedían a éste que los pusiera a disposición de la Dirección de Seguridad, aunque fuera en una prisión. Pero ni aun así. La cárcel central fue incendiada muriendo todos menos dos. Entre los fallecidos estaban republicanos como Melquiades Álvarez, jefe del Partido Republicano Liberal y Rico Avello, exministro del interior.

Como resultado de ese terror en la retaguardia los entusiasmos por la República democrática se enfriaron en cada vez más personas al ver con sus ojos la suerte que podía depararles el triunfo sobre los insurrectos: "poco a poco, a los ojos del pueblo republicano pero pacífico, liberal pero amante del orden, demócrata pero temeroso de la anarquía aún más que de la dictadura, el gobierno republicano perdía su carácter de legítimo y legal adquirido por las elecciones" (Ibid: 166). Los milicianos con su conducta, consentida por el gobierno, mancillaron la legitimidad de la defensa, con lo que la opinión pública se fue alejando poco a poco de la causa.

La explicación del terror (Campoamor llega a llamar terroristas a los milicianos) por parte del gobierno no fue fácil. En ocasiones, trató de echar la culpa de los excesos a los anarquistas, y en otras a la necesidad de luchar contra los quintacolumnistas. Sin duda, el peso de los anarquistas fue relevante en Madrid, pero menos que en Barcelona donde fueron capaces de que todo un consejero de gobernación de la Generalitat, el Sr. España, debiera huir a Francia al temer por su vida. Campoamor cita igualmente ejemplos de ejecuciones en Barcelona, recuperando su vena feminista: "de tantos asesinatos execrables, los más odiosos fueron, como siempre, reservados a las mujeres, apaleadas y ultrajadas antes de perder la vida" (Ibid: 182). En todo caso, el gobierno era 
responsable de haber entregado las armas sin ser luego capaz de hacerse con el control de las calles, aunque tampoco lo intentara con gran entusiasmo.

\subsubsection{El gobierno legítimo y el futuro de la guerra (Casp. XVI-XX, 183- 214)}

La legitimidad del gobierno republicano no sólo se fue perdiendo por su consentimiento con los abusos y crueldades de las milicias, sino por su deriva radical. Tras Giral, ocupó la presidencia del Gobierno Largo Caballero por la sola voluntad del Presidente de la República; los partidos republicanos ya no contaban. Las Cortes se convocaron un mes después para tratar de ofrecer una apariencia de legalidad constitucional, pero sólo aparecieron 100 diputados de 470. No sólo faltaron los de la oposición, que ya a esas alturas temían por su vida, sino 160 del bloque de la mayoría de izquierda. Madrid se fue quedando sin legaciones extranjeras (algunas habían sufrido ataques de las milicias), salvo la soviética, cuyo embajador Sr. Roseberg llegó a sentarse en alguna reunión del Consejo de Ministros. A partir de ese momento la inclinación hacia el bloque soviético por parte del gobierno resultará evidente.

Campoamor describe cómo, poco a poco, los países en principio aliados de la República la abandonan. Prieto consideraba que el gobierno ganaría la guerra porque contaba con el oro para comprar armas, lo que suponía una clara ventaja frente a sus adversarios, ya que la moneda española había dejado de tener curso legal en el extranjero. Pudieron en efecto comprar algunos aviones Douglas y municiones, pero paulatinamente el único proveedor de armas sería el gobierno soviético. Esta opción llevaría a que los aliados no sólo no intervinieran durante la guerra civil, sino tampoco después de la segunda guerra mundial, una vez derrotadas las potencias del eje que habían ayudado al ejército de Franco. Campoamor considera que la guerra civil dejó de ser un "asunto privado" de España para pasar a ser el frente de actuaciones, desde la trastienda, entre el comunismo y el fascismo, lo que hizo que el resto se apartara. Los españoles se mataban entre sí, desconociendo que en realidad eran marionetas que servían intereses que iban más allá de los Pirineos. Todo daba igual. Una vez instalada la política del resentimiento ciego e insatisfecho no había vuelta atrás. A partir de un cierto momento ya no se busca la victoria, que se aventura cada vez más difícil, sino que el precio de la derrota sea el más alto posible para todos. Los lemas que guiarán entonces la política del Frente Popular serán: "Quedarse ciego con tal de otro se quede tuerto" y "iQue todo se hunda con nosotros si no podemos dirigirlo!". Campoamor termina esta parte preguntándose con angustia "lo que el pueblo español, herido y arruinado por la sacudida, conseguirá salvar de los escombros del amado templo, donde a pesar de todo habrá que seguir viviendo" (Ibid: 214). 


\section{Lecciones de Campoamor para el mundo de hoy}

Quien mejor conoció a Campoamor, su amiga Antoinette Quince, la definió como "republicana y liberal", si bien destacaba su dolor "y el de los republicanos liberales ante el terrible fracaso de sus esfuerzos" (Campoamor 2018a: 95 y 96). De hecho, no sabemos si hoy Campoamor sería todavía republicana o apoyaría la monarquía constitucional que tenemos -salvo la reliquia estrambótica de la prevalencia del varón en la sucesión-, que de hecho va a heredar una mujer. Tampoco sabemos qué diría hoy sobre la evolución del "nuevo" feminismo, una vez conseguidas sobradamente todas las reclamaciones que encabezó en su época, salvo tal vez la brecha salarial. Difícil saberlo, tan difícil como aventurar si el propio Marx sería marxista hoy.

Pero lo que no cabe duda es que nos ha dejado más de una lección que aprender o sobre la que reflexionar. Al menos tres. La primera: que por encima de la ideología se encuentra la honestidad personal. La segunda: que para analizar las causas de un fenómeno (sea el machismo o el fracaso de la República) no podemos quedarnos en las primeras explicaciones superficiales, sino que hay que profundizar en la causa de la causa. La tercera: que sin autocrítica no hay aprendizaje, pues estaríamos condenados a repetir los mismos errores una y otra vez.

Tras el fracaso estrepitoso de nuestras dos experiencias republicanas cabe aventurar el fracaso de un posible tercer intento si previamente no se hace un análisis riguroso de "todas" las causas, más allá del fácil recurso de echar la culpa de todo a "los otros". En este sentido, no podrá haber en España una República digna de tal nombre hasta que los que presumen de republicanos no hagan autocrítica de su actuación durante los últimos intentos históricos, pues bien pudiera ser que, advertida o inadvertidamente, los mayores enemigos de una República española fueran la mayor parte de los que más fervientemente se declaran republicanos.

En este contexto, Campoamor se presenta como un eficaz antídoto contra el sectarismo y la doble vara de medir, verdaderos obstáculos para un proyecto de vida en común en España (Ibáñez 2020: 185-195). Hasta el punto de que no se entiende por qué, siendo una de las primeras mujeres políticas, feminista y republicana, su libro, junto a otros, no resulte de lectura obligada en todas las escuelas de España para entender de verdad nuestra historia.

Campoamor decía a propósito del Madrid de los primeros tiempos de la guerra: "La más leve apariencia de hostilidad contra el gobierno era de inmediato castigada con la muerte por las patrullas de milicianos. Una consigna fue rápidamente difundida, la del optimismo a la fuerza: 'Nunca pasa nada, y si alguna vez pasa, no importa"” (2018, p. 168). Pues bien, hoy ocurre algo semejante, la más leve sugerencia de necesidad de autocrítica es 
de inmediata acallada y castigada con el rápido recurso a un eslogan o a una etiqueta descalificadora. Los malos necesariamente son sólo los del otro bando y si "los nuestros" cometen errores y horrores similares hay que responder con vehemencia todos a una, prietas las filas: "Eso es falso, y si pudiera ser cierto, no importa".

\section{Bibliografía:}

Campoamor, Clara (2001): Mi Pecado Mortal. El Voto Femenino y Yo. Sevilla: Instituto Andaluz de la Mujer

Campoamor, Clara (2006): España, La Condición de la Mujer en la Sociedad Contemporánea (traducción y estudio introductorio de Ana Álvarez Parrondo).

Oviedo: Instituto Asturiano de la Mujer

Campoamor, Clara (2013): El pensamiento vivo de Concepción Arenal. Madrid: Espuela de Plata.

Campoamor, Clara $\left(2018 \mathrm{a}^{6}\right)$ : La revolución española vista por una republicana (edición de Luis Español Bouché). Sevilla: Escuela de Plata

Campoamor, Clara (2018b): El derecho de la mujer. Valencia: Tirant humanidades/Colegio de abogados de Madrid

Gibson, Ian (19825): La noche que mataron a Calvo Sotelo. Barcelona: Argos Vergara

Ibáñez, Alberto G (2020): La Guerra cultural. Los enemigos de España y Occidente. Córdoba: Almuzara

Juliá, Santos (2009): La Constitución de 1931 (Vol. VIII) en Artola, Miguel (dir.), Colección Las Constituciones españolas. Madrid: Iustel

Lerroux, Alejandro (1963): La pequeña historia. Madrid: Afrodisio Aguado Editores

Manzanero, Delia (2019): "La modernización del sistema educativo y penitenciario de la mujer: el impacto de la herencia krausista en la obra de Concepción Arenal”, Araucaria, 43, 537-559

Trapiello, Andrés (2019): Las armas y las letras. Literatura y guerra civil (1936-1939). Barcelona: Destino

Tusell, Javier (1984): "Diego Martínez Barrio: Memorias inéditas. Por qué fracasó la República", Revista Historia 16, 93, 21-34

Zugazagoitia, Julián (1968): Guerra y vicisitudes de los españoles. París: Librería española 